\title{
New Normal Role in PM2.5 Reduction in Bangkok
}

\author{
Sopa Chinwetkitvanich, Thawat Ngamsritrakul, and Sirima Panyametheekul
}

\begin{abstract}
The world has been exposed to the Coronavirus Disease 2019 (COVID-19) since late 2019. A global pandemic has shifted health concerns from air pollution effects to novel coronavirus disease, similarly to those in Bangkok. Although Bangkokians have experienced severe PM2.5 conditions since the last quarter of 2017, the related agencies have failed to elucidate the crisis. This has been because the fundamental air quality management is focused on controlling emissions. The Thai government has sluggishly determined the situations that lead to the inability to clean up its air. How are air pollution and disease linked? This article points to the importance of source management. The lockdown measures revealed reduced traffic rate and PM2.5 concentrations. Such a close relationship has shed insights of the consequences of working from home (WFH). The link between disease and air pollution includes (i) WFH regulation is one specific way to prevent the transmission of disease, (ii) this guideline decreases traffic congestion in an urban city which is one path of diminished pollution discharge and (iii) then noticeably followed by PM2.5 reductions. Again, the magnitude of source control is crucial. Reducing pollutions from traffic by means of WFH has illustrated this accomplishment. In the midst of this crisis, moving to a new normal role supports remaining protected from both air pollution and the pandemic. Nevertheless, the sustainability of transportation control in an overcrowded city like Bangkok should be considered as a vital pathway to tackle air pollution.
\end{abstract}

Index Terms-Air quality monitoring, COVID-19, Sustainable cities and communities, traffic index.

\section{INTRODUCTION}

The aspect of air pollution, especially PM2.5 (particulate matter with diameter less than 2.5 micrometers), has become a public health challenge for Thais during the last quarter of 2017. Haze caused by particulate matter emissions from agricultural biomass burning has arisen for years before. However, the PM2.5 situation in the Bangkok Metropolitan Area exceeding the ambient air quality standard [1] during the last quarter of 2017 continuing to the first quarter of 2018 reached hazardous levels. That is, they obviously lowered visibility and irritated (or even damaged) respiratory function Also, the problems associated with PM2.5 were prolonged beyond the usual due to uncommon atmospheric conditions resulting in more difficulty in dispersing pollution. Hence, a second PM2.5 crisis from 2018 to 2019 has forced

Manuscript received August 20, 2020; revised February 1, 2021.

Sopa Chinwetkitvanich is with the Department of Sanitary Engineering, Faculty of Public Health, Mahidol University, Thailand (e-mail: Sopa.chi@mahidol.ac.th).

Thawat Ngamsritrakul is with the Defense Engineering and Technology, Faculty of Engineering, Chulalongkorn University, Bangkok, Thailand (e-mail: kim.ngamsritrakul@gmail.com).

Sirima Panyametheekul is with the Department of Environmental Engineering, Faculty of Engineering, Chulalongkorn University, Bangkok, Thailand (e-mail: Sirima.P@chula.ac.th)
Bangkokians to adapted to the new normal of wearing N95 masks daily for health protection ever since. Actually, PM2.5 has become a seasonal phenomenon for years and its severity seems to have worsened.

The world has officially been exposed to the Coronavirus Disease 2019 (COVID-19) since December 2019, which is defined as an illness caused by a novel coronavirus now called severe acute respiratory syndrome coronavirus 2 (SARS-CoV-2). On January 30, 2020, the WHO declared the COVID-19 outbreak a global health emergency, and declared a global pandemic on March 11, 2020. Due to this situation, most socio-economical activities were reduced or ceased on both national and international scales. This pandemic has affected travel and transportation norms the most. Every country has been forced to close its borders and transportation both inbound and outbound to control the epidemic. On the other hand, the diminution of socio-economical activities has the effect of reducing environmental pollution and fortunately improving environmental quality. Air pollution in major cities in the world has been reported to decline during the COVID-19 circumstance [2]-[7]. Explanations were in perfect accord in that better air quality was due to the reduced emissions.

Thailand has also declared several measures to prevent the epidemic, e.g., social distancing, work from home (WFH) etc. March 16 $6^{\text {th }}$, the Centre for COVID-19 Situation Administration (CCSA) of Thailand declared lockdown measures. During this period, both traffic volume and PM2.5 concentrations decreased regarding to the consequence of WFH and lockdown due to the relationship between PM2.5 concentrations and transportation volume. Hence, the WFH is the new normal that should constitute the proper way to deal with both crises (PM 2.5 and COVID-19). This research aimed to (a) study the relationship between PM2.5 concentrations from three air quality monitoring stations in the central part of the Bangkok Metropolitan Area and the traffic index during the periods of PM2.5 crisis and lockdown measures and (b) to compare PM2.5 concentrations between two consecutive years (2019 and 2020) including lockdown measures.

\section{Methodology}

\section{A. Air Quality Monitoring Data}

The PM2.5 concentrations observed from November to April of two consecutive years (2018-2019 and 2019-2020) were compared among three monitoring stations and discussed. First, the station operated by Chulalongkorn University (CU) is located at the Department of Environmental Engineering, Faculty of Engineering. The other two stations, administered by the Bangkok 
Metropolitan Administration (BMA), are located at the roadside in front of Samyan Mitrtown Building, Pathumwan District (PTW), and at Nararom Intersection, Bangrak District (BR) [8]. The observed PM2.5 concentrations from these three monitoring stations were illustrated to compare with WHO air guidelines of $25 \mu \mathrm{g} / \mathrm{m}^{3}$.

\section{B. Meteorological Data}

In addition to air quality monitoring data, meteorological data and hot spots during certain days were retrieved from the regional haze situation report of the ASEAN SPECIALISED METEOROLOGICAL CENTRE [9].

\section{Transportation Data}

Statistics of transportation volume during the COVID lockdown measure was retrieved from the public relation information reported on the website of the Ministry of Higher Education, Science, Research [10]. Also, the change in transportation volume due to the COVID-19 crisis was retrieved from the Facebook webpage of the Transportation Institute of Chulalongkorn University (CUTI) [11]. The traffic index was retrieved from the Longdo Traffic Index website [12].

\section{DISCUSSIONS}

PM2.5 concentrations from three monitoring stations during November of 2018 and 2019 are exhibited in Fig. 1. The number of days that PM2.5 was observed exceeding WHO guidelines $\left(25 \mu \mathrm{g} / \mathrm{m}^{3}\right)$ in 2019 was higher than that in 2018 for all stations. That is, during November 2019, the number of days when average PM2.5 concentrations were higher than WHO guidelines were 10, 26 and 30 days at the stations of $\mathbf{C U}$, Nararom Intersection of $\mathbf{B R}$ and Samyan Mitrtown roadside of PTW, respectively. However, the number of days exceeding WHO guidelines in 2018 were 1, 23 and 26 days, respectively. Among the three stations, PTW roadside station observed the higher number of days (PM2.5 exceeded WHO guidelines) exceeding those of others because of traffic and the construction of Samyan Mitrtown Building during that period. However, the $\mathbf{C U}$ station showed lower daily PM2.5 concentrations and fewer days exceeding WHO guidelines than the other stations because the station was not located in a roadside area.

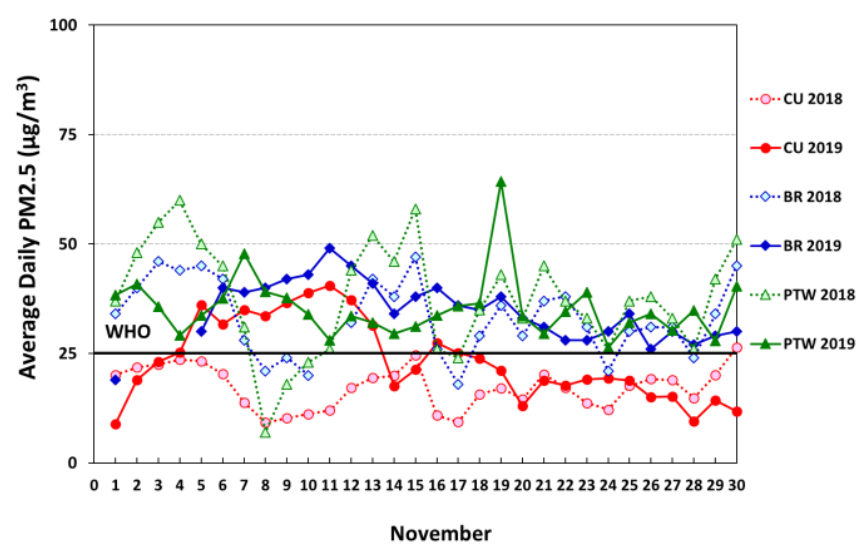

Fig. 1. Average daily PM2.5 concentrations in November (2018 and 2019).

Fig. 2 shows the average daily PM2.5 concentrations monitored during December of 2018 and 2019. Similar to November, the number of days that ambient PM2.5 exceeded WHO guidelines of $25 \mu \mathrm{g} / \mathrm{m}^{3}$ in 2019 was more than those in 2018. At the $\mathbf{C U}$ station, 9 and 16 days exhibited average daily PM2.5 concentrations higher than $25 \mu \mathrm{g} / \mathrm{m} 3$ (WHO guideline) in 2018 and 2019, respectively. For roadside locations, BR station showed 27 and 29 days, which PM2.5 values were over WHO guidelines in 2018 and 2019, respectively, while PTW station observed 28 and 30 days, respectively.

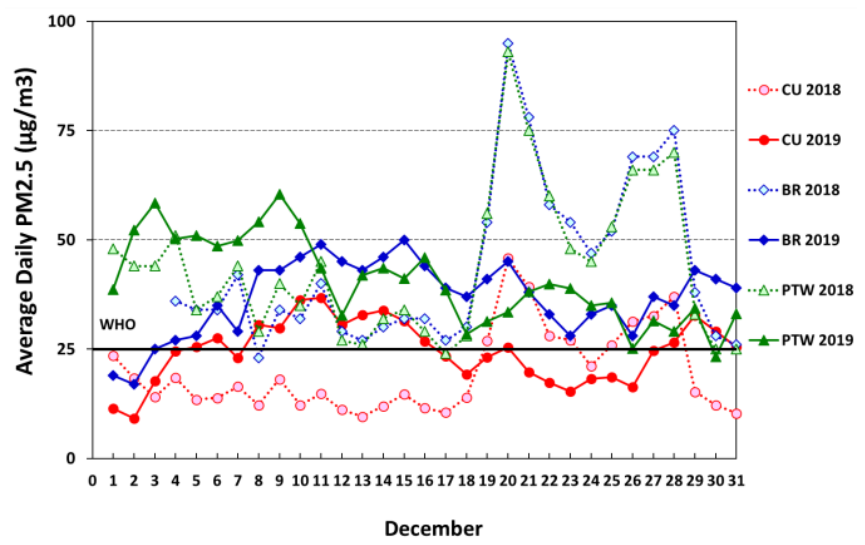

Fig. 2. Average daily PM2.5 concentrations in December (2018 and 2019).

During January in (Fig. 3), the number of days PM2.5 exceeded WHO guidelines in 2020 (21 days) was higher than those in 2019 (15 days) at the CU station. Likewise, the other two stations, which were roadside stations, showed the number of days in 2020 was more than those in 2019. That is, BR station showed average daily PM2.5 concentrations higher than WHO guidelines reported for 22 and 27 days in the years 2019 and 2020, respectively. Similarly, PTW District station reported 29 and 31 days that in 2019 and 2020 PM2.5 exceeded WHO guidelines, respectively.

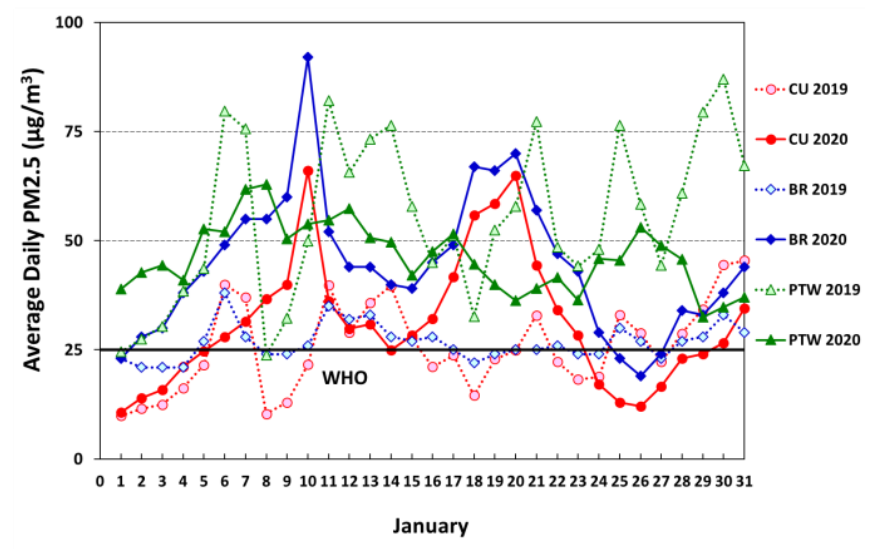

Fig. 3. Average daily PM2.5 concentrations in January (2019 and 2020).

The severity of PM2.5 situations in Bangkok clearly developed during January (Fig. 3) and February (Fig. 4). However, the PM2.5 crisis showed a sigh of relief in March and April due to increase of ambient temperature and influence of seasonal southern winds, resulting in greater pollution dispersion. Fig. 4 shows average daily PM2.5 concentrations in February of 2019 and 2020. The number of days that PM2.5 was higher than $25 \mu \mathrm{g} / \mathrm{m}^{3}$ in 2020 was reported more than those in 2019. As such, the number of 
days PM2.5 exceeded WHO guideline in February of the year 2019 were 2, 5 and 9 days for stations of $\mathbf{C U}, \mathbf{B R}$ and PTW respectively, while number of days in 2020 were 21, 20 and 27 days, respectively. From January to February, not only local sources of PM2.5 (such as traffic volume, open burning), but also thermal inversions* in the atmosphere sometimes occurred in the Bangkok area, resulting in difficulty for pollution to disperse.

*The warmer air rises and acts as a lid trapping the colder air close to the ground. Pollution, including that from road traffic, is also trapped, so the air layer closest to the ground becomes more polluted. This continues until the prevailing meteorological conditions change.

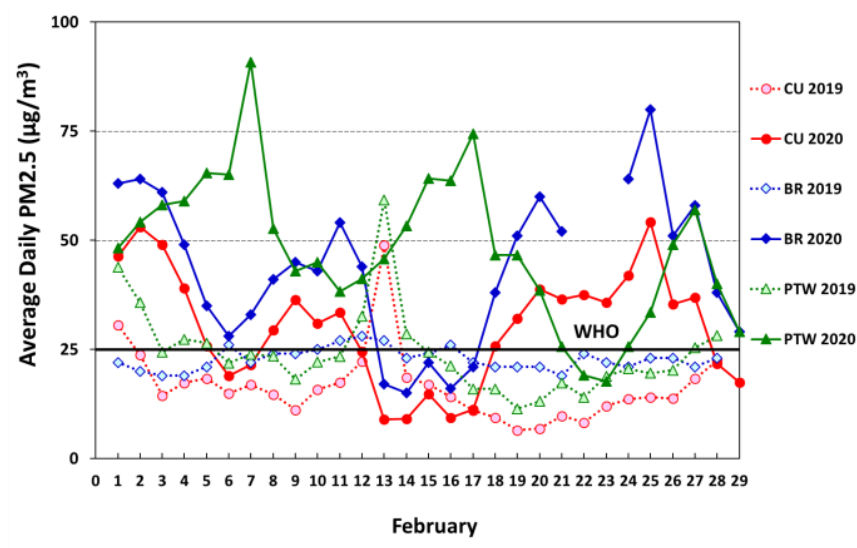

Fig. 4. Average daily PM2.5 concentrations in February (2019 and 2020).

Average daily PM2.5 concentrations observed during March of 2019 and 2020 are exhibited in Fig. 5. Differently, the number of days PM2.5 exceeded WHO guidelines at the CU station was found for 2 days in the year 2020, which was fewer than that found in 2019 (19 days). However, BR station still presented the higher number of days exceeding WHO guidelines in 2020 (15 days) than 2019 (8 days), similar to those that occurred in previous months. In the case of PTW station, the lower number of days exceeding WHO guidelines was observed in 2020 (10 days), while 18 days exceeding guidelines was reported in 2019.

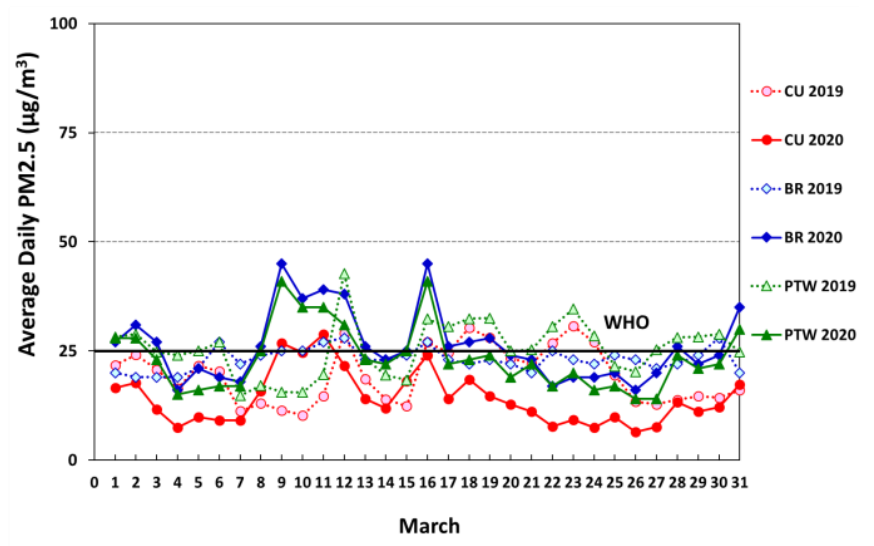

Fig. 5. Average daily PM2.5 concentrations in March (2019 and 2020).

During April, PM2.5 concentrations were mostly less than WHO guidelines of $25 \mu \mathrm{g} / \mathrm{m}^{3}$ as shown in Fig. 6. At the CU station, only one day in 2020 averaged daily PM2.5 concentrations higher than the WHO guidelines, while there was none found in 2019. Nevertheless, two roadside stations still recorded some significant amounts of PM2.5 exceeding the guidelines during 2020. That is, 8 and 9 days were found at BR and PTW stations, respectively. However, the situation of PM2.5 at these two roadside stations in 2019 was much better, that is, none and only 2 days were observed, respectively.

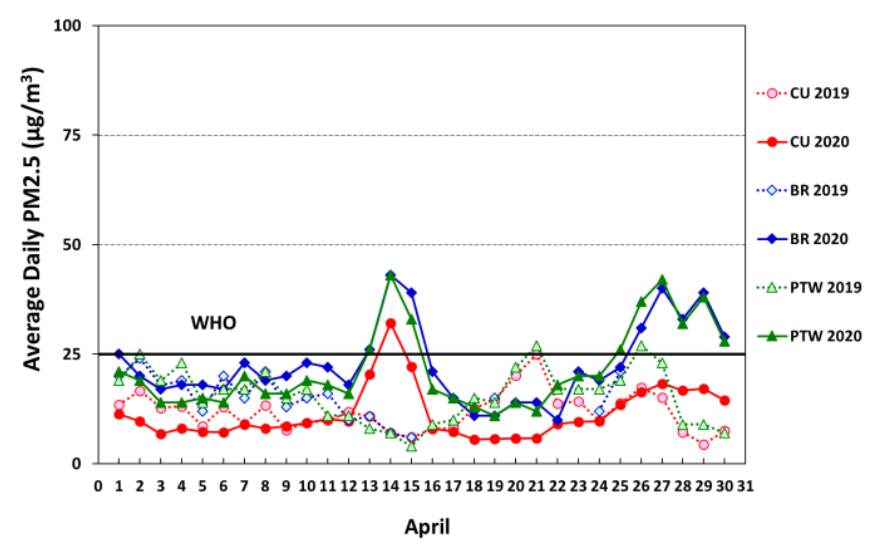

Fig. 6. Average daily PM2.5 concentrations in April (2019 and 2020).

Usually, PM2.5 crisis in Bangkok showed severe signs from November to February, then relieved conditions in March and April due to seasonal atmospheric condition. Statistically, the PM2.5 situations tend to be more severe every year as shown by the increased number of days that PM2.5 concentrations exceeded the standard in this article. Although several attempts from governmental agencies including various policies were implemented to reduce the crisis, they seemed to be ineffective. Unfortunately, still no explicit solution has been found for this case because of the arguments regarding sources contribution for PM2.5 in the Bangkok area still remained. The related article titled, "PM2.5 is coming back again" already discussed the various sources affecting PM2.5 situations in Bangkok [13]. The authors mentioned that vehicles, particularly diesel engine, obviously influenced PM2.5 concentrations.

Several studies attempted to identify sources of PM2.5 emissions in the Bangkok area [14]-[16]. Motor vehicles, especially diesel fuel type, were mentioned to play an important role in PM2.5 concentrations in Bangkok. Heavy traffic in an urban area also enhanced PM2.5 emissions, resulting in worsening the crisis as well [16]. Truthfully, traffic volume should be associated with PM2.5 crisis, but appropriate information of traffic volume could not yet be found. Instead, traffic index [12] and congestion level [17] were determined revealing no significant difference. That is, the averages of traffic index were 3.8 and 3.9 for 2018 and 2019 , respectively. The averages of congestion levels (percentages of more travel time taken in comparison with baseline uncongested condition) of these two consecutive years (2018 and 2019) were both 53\%.

Therefore, an increase of PM2.5 severity would possibly be involved with some other factors, such as, vehicle age, biomass burning in the vicinity of the Bangkok area, or secondary PM2.5 behaviors etc. Also, abnormal meteorological conditions, e.g., inversion or calm wind, retarding the dispersion of air pollution were observed more often or longer period.

Due to the outbreak of COVID-19 at the end of December 
2019 with rapid increase of infected individuals, the government has implemented various policies to mitigate the COVID-19 situation. For instance, the establishment of the Center for COVID-19 Situation Administration (CCSA), the cabinet resolution of long holidays cancellation (to prevent massive transportation), enacting the Emergency Decree, especially lockdown measure, as well as requesting for cooperation such as WFH or overlapping office hours etc., as exhibited in Fig. 7. Those measures of lockdown, WFH or office hours overlap consequently affected transportation in Bangkok as exhibited with the declining blue line representing "total passengers" in Fig. 7.

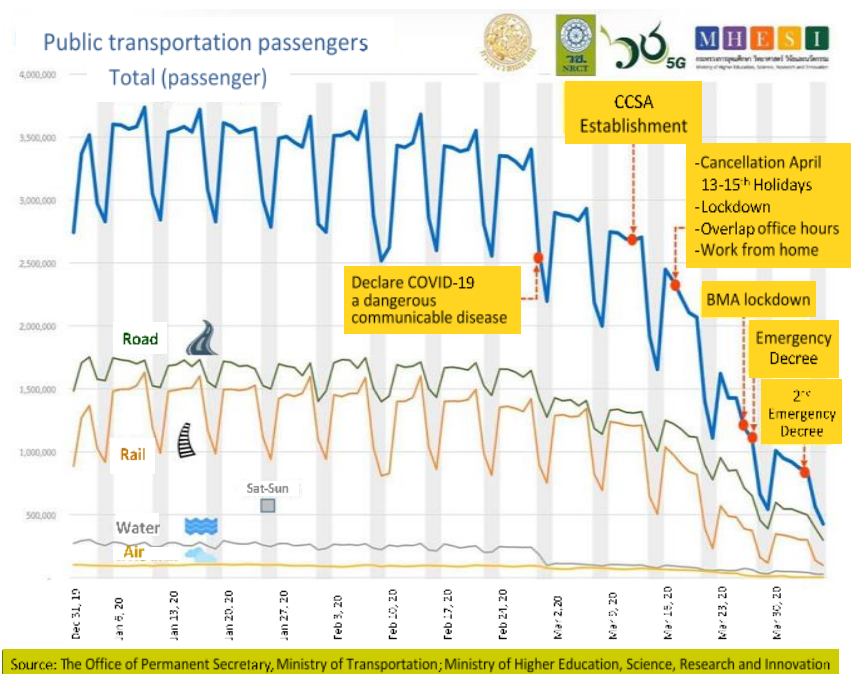

Fig. 7. Public transportation situation during the COVID19 lockdown measure. (https://www.mhesi.go.th)
Change in Transportation of Bangkok people due to COVID-19 crisis

(Percentage of people who travelling in Bangkok area with only one transportation)

\section{No transportation (A) : 48.75}

Personal car (B) : 51.68

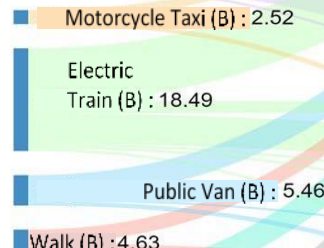

Fig. 8. Change in transportation of Bangkok people due to COVID-19 crisis. (Source: Transportation Institute of Chulalongkorn University)

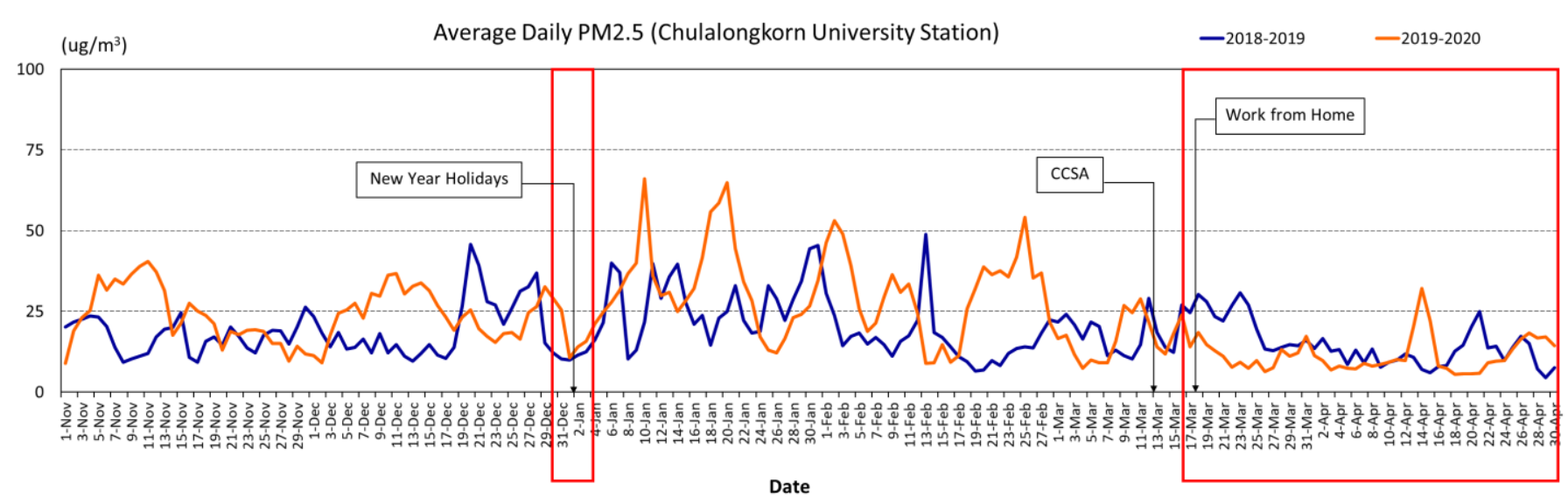

Fig. 9. Average daily PM2.5 concentrations at Chulalongkorn University Station during November to April (2018-2019 versus 2019-2020).

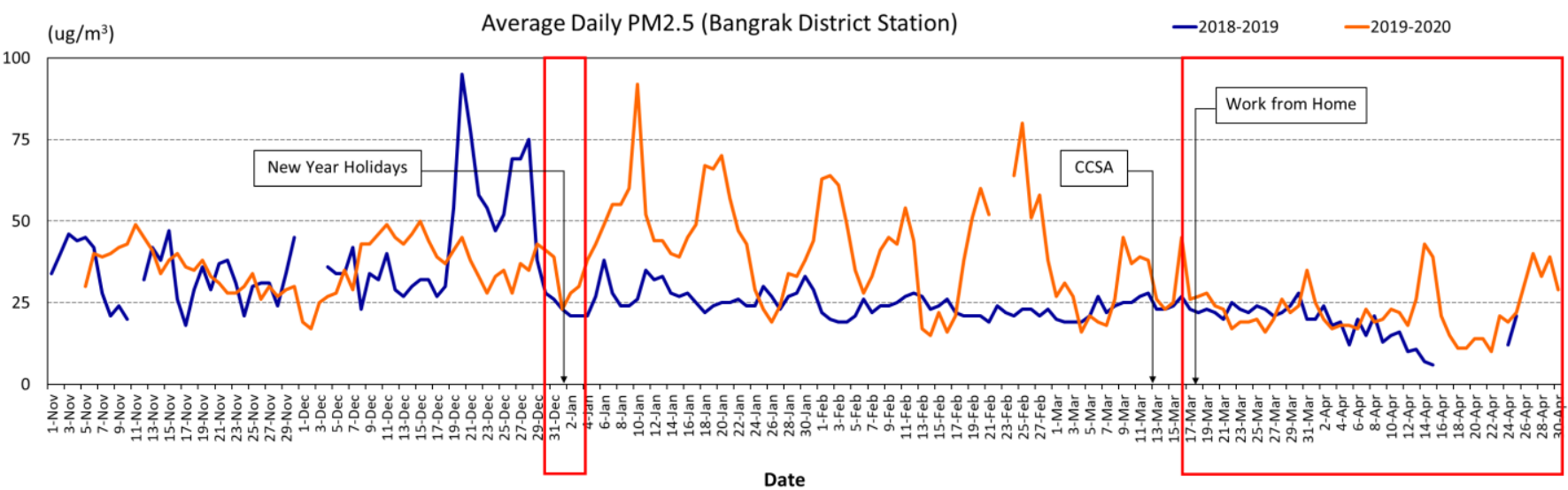

Fig. 10. Average daily PM2.5 concentrations at Bangrak District Station during November to April (2018-2019 versus 2019-2020). 


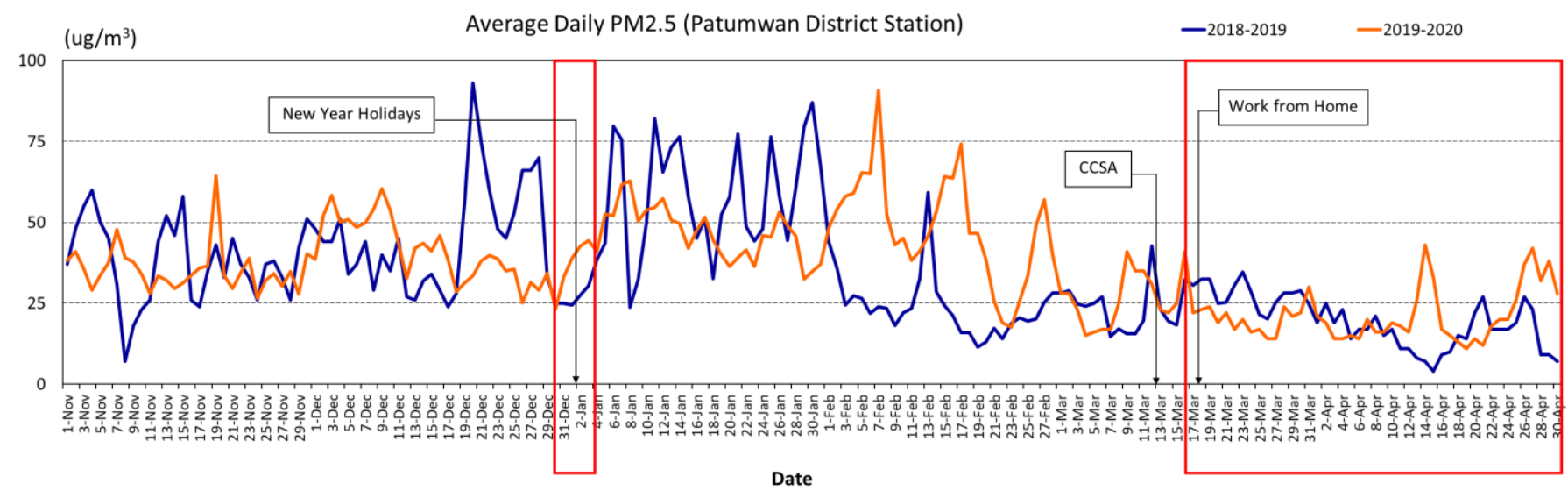

Fig. 11. Average daily PM2.5 concentrations at Pathumwan District Station during November to April (2018-2019 versus 2019-2020).

CUTI distributed online questionnaires via their official Facebook platform since April 2, 2020 and presented their results via the same platform on April 20, 2020 [11]. One of their questionnaire results as shown in Fig. 8 has described how Bangkokians adjusted their transportation patterns due to the COVID-19 situation. That is, the whole transportation was reduced by $49 \%$ after COVID-19 administration, for which personal car contributed $20 \%$ reduction while the others contributed about $29 \%$. Therefore, traffic volume during the lockdown was obviously lighter than before the COVID-19 crisis.

Hence, the lighter traffic volume due to the crisis administration was associated with favorable meteorologic conditions helped reduce ambient PM2.5 concentrations in the Bangkok area as shown in Figs. 9 to 11. The ambient monitoring data from three designated stations, i.e., CU, BR and PTW stations, since the crisis administration (March 17, 2020) presented the decrease of PM2.5 concentrations to a range similar that occurring during New Year's holidays (December 31, 2019 to January 2, 2020). In comparison between a nonroadside station $(\mathbf{C U})$ and two roadside stations (BR and PTW), higher PM2.5 concentrations were clearly observed from roadside stations during the observed years (Fig. 9 to 11).

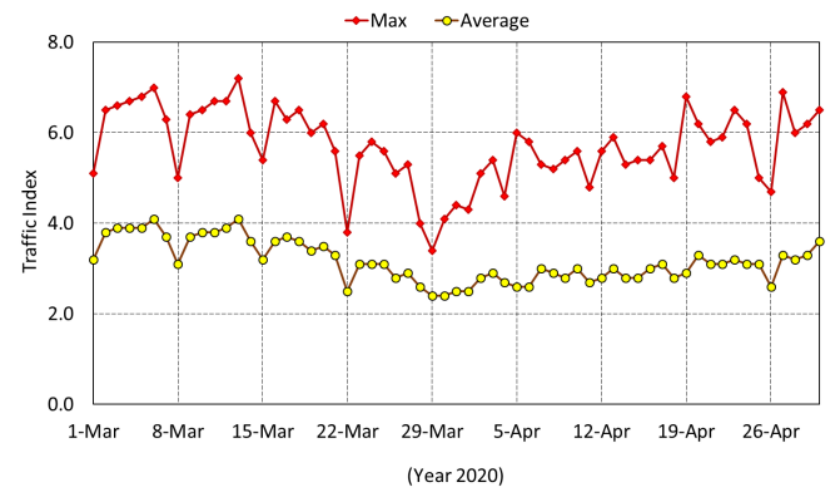

Fig. 12. Traffic index in Bangkok area [12].

However, some spiked peaks of PM2.5 occurred from April 1210 14, 2020 (higher than $25 \mu \mathrm{g} / \mathrm{m}^{3}$ ) although they were in the middle of lockdown measures. This incident was questioned as traffic volume, which is one of PM2.5 emission sources, was evidently lessened due to the lockdown and WFH measures as shown in Figs. 7 and 8. Furthermore, the traffic index during March and April, 2020 (Fig. 12) showed that their daily averages and maximum peaks were obviously reduced since BMA lockdown measures on March 26, 2020, and remained almost the same low level from April $12^{\text {th }}$ to 14 , 2020.

Then the meteorological wind speed and direction as well as NOAA hot spot data from April 11 to 14, 2020 were considered and discussed. According to Fig. 13, they illustrated that the wind from April 11 to 14, 2020 was quite diminished; therefore, this could be the explanation of the incident (spiked peak of PM2.5 from April 12 to 14, 2020) because the diminished wind possibly weakened the dispersion of PM2.5.

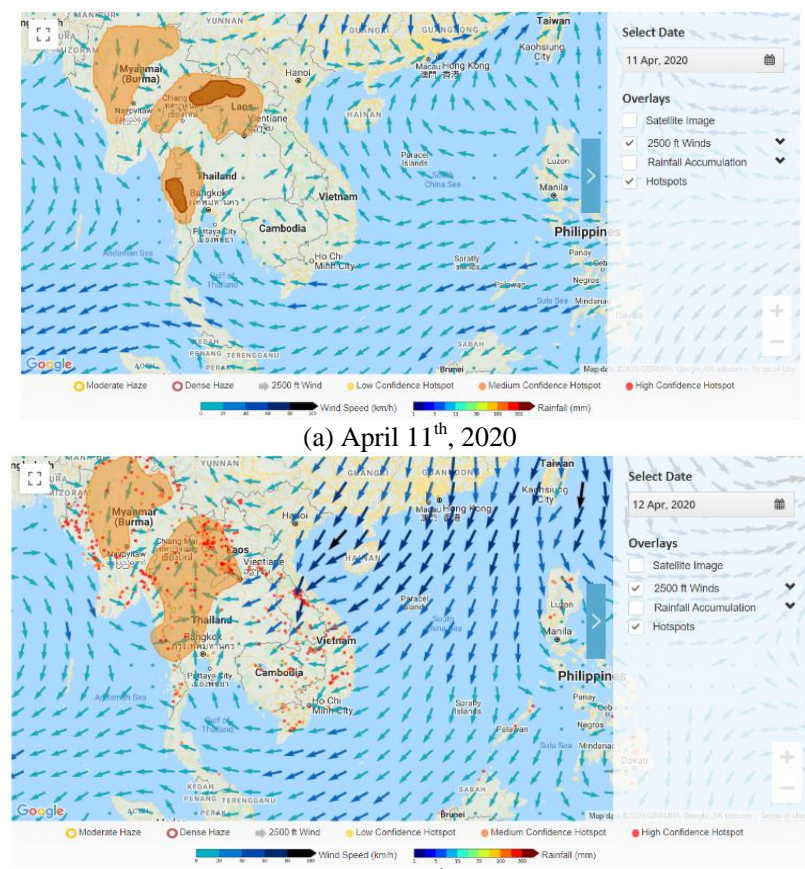

(b) April $12^{\text {th }}, 2020$
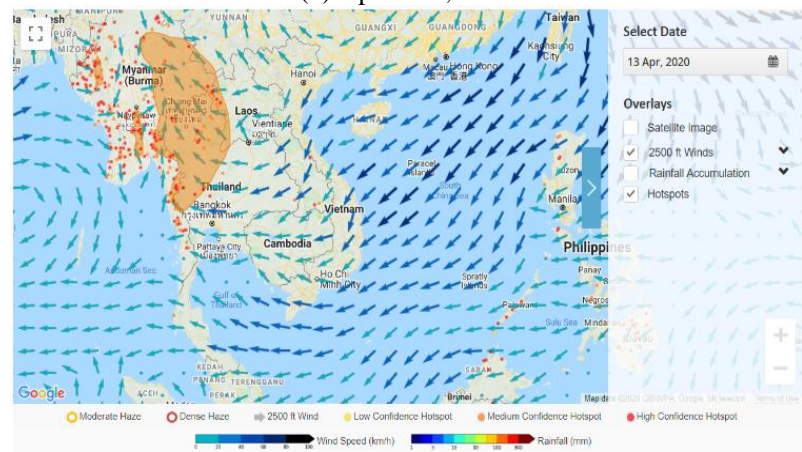

(c) April $13^{\text {th }}, 2020$ 


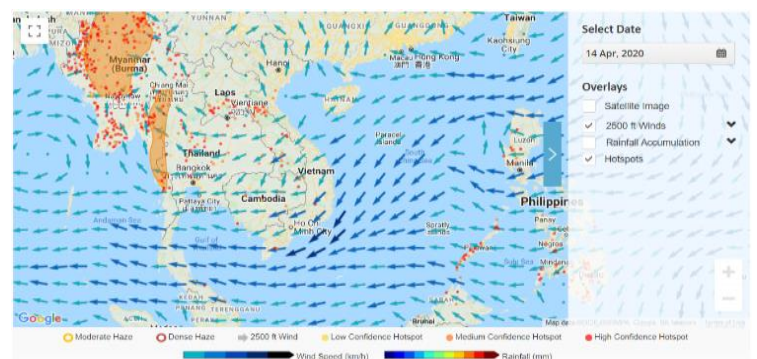

(d) April $14^{\text {th }}, 2020$

Fig. 13. Wind speed and direction as well as NOAA hotspot during April 11 $-14^{\text {th }}, 2020$. (Source: asmc.asean.org) [9].

\section{CONCLUSION}

Usually, the PM2.5 crisis in Bangkok and perimeter areas occurs from November to February. However, any meteorological inversions could significantly enhance PM2.5 concentrations from their usual range due to less dispersion capability. The ability to accurately predict inversion incidents should assist decision makers to affirm any strategic urgent response to the situation.

Moreover, future PM2.5 situations are likely to be more severe due to the lack of an effective response to the crisis so far. Therefore, people will have to wear masks (face mask, N95 mask or face shield) as their new normal behavior to protect themselves from pollution and contagious diseases. Further details on how to select the most appropriate type of mask were mentioned [18]. In addition, the WFH measures with proper technology and devices have been proved to be an alternative approach to relieve the PM2.5 crisis long term.

Additionally, some governmental strategies and approaches were academically proposed for long term response to the PM2.5 situation in Bangkok and perimeter areas. That is, sulfur content in fuel oil should be reduced to lower than $10 \mathrm{ppm}$ level before 2024. The completeness of the public transportation network should be expedited, including of provision of secure pavement for bicycles and pedestrians to enhance pollution-free travel. The balance of public transportation and other vehicles remain an important key to manage PM2.5 emissions.

\section{CONFLICT OF INTEREST}

The authors declare they have no conflict of interest.

\section{AUTHOR CONTRIBUTIONS}

Sopa Chinwetkitvanich contributed to data retrieval, data graphical analysis and major manuscript preparation. Thawat Ngamsritrakul contributed to data retrieval, data graphical analysis and initial manuscript writing. Sirima Panyametheekul (corresponding author) contributed to article design and revision of the final manuscript.

\section{ACKNOWLEDGMENT}

The authors wish to thank the Air Quality and Noise Management Division, Bangkok Metropolitan Administration for providing air quality monitoring data. Authors also thank Thailand network center on Air Quality Management (TAQM) for their support and assistance. Finally, special thanks to HAUS IAQ Research Unit,
Chulalongkorn University for their support.

\section{REFERENCES}

[1] Air Quality and Noise Management Bureau, Pollution Control Department. Thailand's Air Quality and Situation Reports. [Online]. Available: http://air4thai.pcd.go.th/webV2

[2] A. Chauhan and R. P. Singh, "Decline in PM2.5 concentrations over major cities around the world associated with COVID-19," Environ. Res., 2020, vol. 187, p.109634.

[3] P. Krecl, A. C. Targino, G. Y. Oukawa, and R. P. Cassino Junior, "Drop in urban air pollution from COVID-19 pandemic: Policy implications for the megacity of Sao Paulo," Environ. Pollut., 2020, vol. 265, p. 114883.

[4] D. Rodríguez-Urrego and L. Rodríguez-Urrego, "Air quality during the COVID-19: PM2.5 analysis in the 50 most polluted capital cities in the world," Environ. Pollut., 2020, vol. 266, p. 115042.

[5] S. Selvam, P. Muthukumar, S. Venkatramanan, P. D. Roy, K. Manikanda Bharath, and K. Jesuraja, "SARS-CoV-2 pandemic lockdown: Effects on air quality in the industrialized Gujarat state of India," Sci. Total Environ., 2020, vol. 737, p. 140391.

[6] J. M. Baldasano, "COVID-19 lockdown effects on air quality by $\mathrm{NO}_{2}$ in the cities of Barcelona and Madrid (Spain)," Sci. Total Environ., 2020, vol. 741, p. 140353

[7] M. D. Adams, "Air pollution in Ontario, Canada during the COVID-19 State of Emergency," Sci. Total Environ., 2020, vol. 742, p. 140516.

[8] Air Quality and Noise Management Division Bangkok. MANUAL REPORT: Manage the Measurement Data Processing Results. [Online]. Available: https://bangkokairquality.com/bma/report?lang=th

[9] Asean Specialised Meteorological Centre. Regional Haze Situation. [Online]. Available: http://asmc.asean.org/home/

[10] Ministry of Higher Education, Science, Research and Innovation (2020). Statistics of Transportation during COVID-19 Situation in Thailand. [Online]. Available: https://www.mhesi.go.th/home/index.php/pr/all-media/56-covid-19/co vid-infostatistic/1417-social-di

[11] Transportation Institute of Chulalongkorn University. (2020). Change in Transportation of Bangkok people due to COVID-19 crisis. [Online]. Available:

https://www.facebook.com/CUTransInst/photos/pcb.2482241388754 $675 / 2482495735395907 /$ ?type $=3 \&$ theater

[12] Metamedia Technology. (2020). Longdo Traffic Index. [Online]. Available: https://traffic.longdo.com/trafficindex

[13] T. Ngamsritragul and S. Panyametheekul. (2018). Particulate matter less than 2.5 micron: PM2.5 is coming back. [Online]. Available at: https://goo.gl/13tsFo

[14] N. T. Quang Hung, S.-B. Lee, N. T. Hang, J. Kongpran, N. T. Kim Oanh, S.-G. Shim, and G.-N. Bae, "Characterization of black carbon at roadside sites and along vehicle roadways in the Bangkok Metropolitan Region," Atmos. Env., 2014, vol. 92, pp. 231-239.

[15] S. Duangkaew, W. Limpaseni, and P. Suwattiga, "Carbon composition of PM10 and PM2.5 in Bangkok ambient air from a city center sampling site," Rangsit Journal of Arts and Sciences, 2013, vol. 3, no. 1, pp. 17-23.

[16] Pollution Control Department. (2018). Study of PM2.5 emission sources and its management in Bangkok and perimeter. [Online]. Available: http://infofile.pcd.go.th/air/PM2.5.pdf?

[17] TomTom International BV. [Online]. Available: https://www.tomtom.com/en_gb/traffic-index/bangkok-traffic/Retriev ed

[18] S. Panyametheekul. (2018). "Air quality index of PM2.5 exceeds the standard" What does this message mean? and How does it deal with people? [Online]. Available: https://goo.gl/e8BdvR

Copyright (C) 2021 by the authors. This is an open access article distributed under the Creative Commons Attribution License which permits unrestricted use, distribution, and reproduction in any medium, provided the original work is properly cited ( $\mathrm{CC} \mathrm{BY} \mathrm{4.0})$.

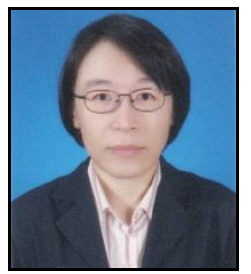

Sopa Chinwetkitvanich has completed a $\mathrm{PhD}$ in environmental engineering from the Faculty of Engineering, Chulalongkorn University, Thailand. She is currently an associate professor in the Department of Sanitary Engineering, Faculty of Public Health, Mahidol University, Thailand. Her research interests are wastewater treatment, environmental monitoring, environmental impact assessment and air quality monitoring. 


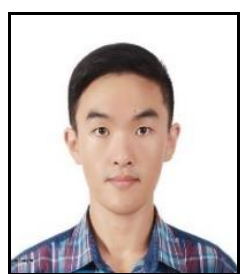

Thawat Ngamsritrakul has completed a bachelor degree in environmental engineering from the Faculty of Engineering, Chulalongkorn University, Thailand. He is currently studying in the master degree of defense engineering and technology,

Faculty of Engineering, Chulalongkorn University,

Thailand. His research interests include air quality monitoring and management, indoor air quality monitoring and management and forest fire management.

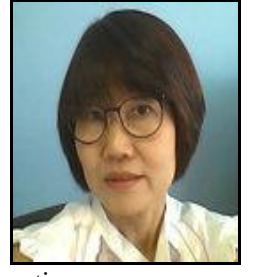

Sirima Panyametheekul has completed a Ph.D. in Environmental Technology from Imperial College University of London, United Kingdom. She is an Associate Professor in the Department of Environmental Engineering, Faculty of Engineering, Chulalongkorn University, Thailand. Her research interests are sustainability of air quality, indoor air quality, good health and well-being and climate 